\title{
Imagination as a Means of Accounting for the Alternation Between Imprisonment and Freedom in James Welch's Novel: The Heart Song of Charging Elk*
}

\author{
Oncioiu Anamaria \\ University of Bucharest, Bucharest, Romania
}

\begin{abstract}
My paper analyzes the issue of the alternation between two complementary concepts which can be analyzed in the novel The Heart Song of Charging Elk: imprisonment and freedom. In order to achieve this goal, I have used several critical theories of authors such as: Michel Foucault, Carl Jung, and Pierre Bourdieu. The analysis is concerned with exploring the alternation between the themes of freedom and imprisonment and the way in which these issues influence the evolution of the main character. I argue that the two themes are in a relation of interdependency and they can be interpreted as opposites from a rational point of view. The rational point of view, although valuable, is, however, incomplete without the exploration of the emotional and subjective factor. This factor can account for the "unreasonable" events from a broader perspective: that of the imagination. As Michel Foucault argues, power exists only in action. Power is also a rather elusive concept. In the same way, the perception of reality can be represented more accurately from a subjective point of view. More exactly, reality is constructed with every thought, emotion, and action of the individual. To sum up, I argue that, from a sociological point of view, the main character is striving to assimilate his personality in a new and hostile cultural environment. On the other hand, from a psychological point of view, he is confronting his inner shadow, as Carl Jung defines the hidden part of the personality. This has a result of the emergence of a genuine sense of self. As the critic Pierre Bourdieu argues, there are a set of common characteristics of taste which define the social belonging of an individual. In the analyzed novel the character manages to adapt to the new situation and to overcome the obstacles that he finds on his way.
\end{abstract}

Keywords: imagination, freedom, imprisonment, evolution, spirituality, culture, religion

\section{Introduction}

My paper is concerned with the analysis of the concept of imagination as it is reflected in the novel The Heart Song of Charging Elk. This concept is used to explain the alternation between the themes of imprisonment and freedom which can be found in the above mentioned novel. I have used several critical theories in order to explain the dynamics of this alternation. These two opposing concepts form a unified picture upon which the core of the narrative is constructed.

\footnotetext{
${ }^{*}$ Acknowledgments: This work was supported by the strategic grant POSDRU/ 187/1.5/S/ 15559 "Competitive Multidisciplinary Doctoral Research at European Level (CdocMD)" cofinanced by the European Social Found within the Sectorial Operational Program Human Resources Development 2007-2013.

Oncioiu Anamaria, Ph.D., Cultural and Literary Studies, University of Bucharest.
} 
As far as the concept of imagination is concerned, I have chosen to study the novel from this perspective, in order to get an insight into the symbolic level of the events narrated. I started from the hypothesis that there must be a deep meaning beyond the suffering presented in the novel. This deep meaning that comes from the transcendence of the suffering is the main concern of my study.

I have used the concept of imagination in order to account for the method in which transcendence is achieved.

The main character of the novel The Heart Song of Charging Elk is recreating reality by means of his imaginative skills. This is how he manages to transcend the suffering he experiences and adapt to the situation in which he is forced to live in. However, this interpretation can be considered one-sided, because it focuses only upon the individual viewpoint. In order to get a clearer perspective, I have also considered the sociological viewpoint.

The sociological point of view is represented by the social and historical context in which the narrative takes place.

\section{Detailed Analysis}

The novel presents the story of a Native American man who is on an adventurous journey of surviving and recovering from a series of traumatic events. These events represent the catalyst that will lead to the achievement of the character's goal: finding his place in the world and achieving a state of mental and emotional balance. The beginning of the story finds Charging Elk in a hospital after he has fallen from a horse and broken his ribs. He had been a member of Buffalo Bill's touring Wild West Show, but, because the show moved on, he was left behind at the mercy of the French governmental bureaucracy. Therefore, he finds himself forced to survive in a strange and hostile land. Under such circumstances, the main character manages to keep his balance by remembering his earlier happy life. This happy life is presented in the novel in deep contrast with the suffering caused by his being arrested, tried, and imprisoned by the provincial French authorities.

The novel brings in question the pursuit of a homeland of the Native American who was dispossessed and moved to reservations after Red Cloud and the other Oglalas were defeated by the United States Army in 1877. This event is important for the main character: both for him as an individual and for him as a member of the Native American community. It reflects the fact that historical events influence every individual. Also, it can be said that, the individual is deeply connected to the cultural and social environment in which he was born and brought up. Charging Elk finds himself in a strange land where he is arrested for vagabondage and, because he acts according to the spiritual values of his society, he ends up in an almost desperate situation. The emotional journey of the hero has a deep symbolic meaning. This deep meaning is connected to the world of the unconscious. It can be argued that the hero is going through a process of diving deep into his unconscious and meeting the challenges of the shadow side of his personality. This shadow side of the personality is not only connected to his personal tribal ancestry, but, it is also connected to a core shadow of the unconscious that belongs to the whole of mankind. Freedom can come only through the confrontation with this dark side of existence. This is why the novel can be seen as a journey of initiation.

The concept of imagination plays a very important role in the development of the character's identity. His sense of self is influenced by complex forces that represent both the inner and the outer world. Charging Elk is using his imaginative skills in order to heal his traumas and manages to achieve balance and find love and happiness in France. Ironically, France becomes a place of both deep suffering and of deep joy. The dark side of 
the personality is transcended through constant personal effort to survive all obstacles. The result is the emerging of the light aspects of the personality. This light aspect is represented by the sublimated form of awareness.

Much of the suffering that the character experienced is connected to the social conflicts and changes which have as a goal the reinforcement of power. The war between the Native Americans and the US also represents a reflection of such a conflict. It can be argued that the bureaucratic system is another expression of exercising political power.

Among the critics who deal with the issue of power is Michel Foucault. In his study "Power and the Question of the Subject", he explains the way in which power functions. He suggests that power represents an elusive concept. This is because it is a phenomenon that exists only in action. The critic states that power as a concrete reality does not exist. He defines this concept as a concrete reality only when it is manifested in human relationships. Power represents for Michel Foucault, an action that influences another action. He talks about the fact that such social phenomena as bureaucracy or concentration camps are results of an excess of political power. This is why the solution does not lie in rationalization.

The novel presents situations in which the character must deal with such phenomena like the French bureaucratic system or the social conflict in which Charging Elk is involved in. Charging Elk has witnessed the battle of Little Big Horn. Part of the suffering associated to the social conflict of his tribe with the US authorities is intensified by his also witnessing the incarceration of the Lakota tribe in the Pine Ridge Reservation. This social conflict represented by war between the United States and the Oglalas in 1877 is the catalyst that leads to Charging Elk's journey of self-discovery. He evokes in his imagination the peaceful and happy life that he experienced for a short while after the defeat of the Native Americans. The last decade of freedom in which Charging Elk and his friend, Strikes Plenty, felt happy, are in deep contrast to the suffering experienced in France. These social events play an important part in his development both as an individual and as a member of the social community.

The fact that he is no longer healthy and free does not stop him from imagining the freedom and health he once experienced in his homeland. His homeland represents both a land of imprisonment and of freedom. It is a land of imprisonment because it has been colonized by the US authorities. On the other hand, it is also a land of freedom, because he has experienced there peace and a sense of communion to his family and friends. Because this situation is not likely to be understood by rational means, it can be argued that it is a paradox. This paradox is best explained by the fact the mind is not entirely confined to the time and space reality. This is why, by means of imagination, the mind can transcend the time-space perspective. I argue that it is because of this characteristic of the mind that Charging Elk manages to transcend his traumatic experiences.

The feelings of guilt are due to the fact that he could do nothing to save his community from the social conflict in which it was involved in. Yet, the character has only these happy memories as a means to stay balanced. It is due to this paradoxical aspect of reality that the literary work can be considered a study of the human mind as well as a reflection of the social and cultural environment of the modern era. The dynamics of this transcendence of the time-space perspective are centered upon the way in which power functions. Power can be understood from different viewpoints. On the one hand, power can be seen from the psychological perspective: the individual who is on an adventurous quest to find happiness and balance, but who encounters deep suffering. This perspective can be analyzed from a mythical and archetypal view point. One the other hand, power can also be analysed as being a force that comes from the outside: a religious authority, a social institution, a family figure, and so on. 
As far as the solution to a better understanding of the concept of power is concerned, the critic Michel Foucault proposes that, in order to explain what society labels as "sanity" and "legality", one must also investigate what is understood as "insanity" or "illegality".

The analysis of the alternation between opposing concepts, offers a broader perspective upon the inner dynamic of forces that are responsible for the development of the individual and of society at large. It can also explain the dynamics of the conflicts which emerge on the way to evolution. It can be said that, Charging Elk can understand the contrast between freedom and enslavement only after having experienced both. This contrast is important because it brings forth the question of man's ability to transcend his suffering.

In order to keep his balance, Charging Elk evokes in his imagination images of his former past happy life. This inner stream of images is important because it offers a perspective upon which the novel can be analyzed as a study of human mental reaction to traumatic events.

From the point of view of psychoanalysis, it can be said that, he is experiencing his inner shadow. The violence and the suffering that he experiences are in fact an expression of the inner fight between good and evil as well as an expression of unconscious collective forces. Therefore, he is on a journey of individuation in which he must deal with his shadow and anima in order to achieve balance. As the novel suggests, the character achieves his inner and outer balance in his relation with his inner unconscious forces. The critic Carl Jung talks about the way in which the human psyche works: It consists of several representative parts that influence one another. These relationships are dynamic and unstable. Hence, the ego must integrate the contents of the unconscious in order to achieve balance.

This is a long and painful process that can last for a long period of time. The integration of the shadow and the anima are the basic parts of this process. In the novel it can be argued that this process, which the psychoanalyst Carl Jung calls individuation, is partially accomplished by means of overcoming the obstacles and the suffering caused by the war and the adaptation to the new country. As far as the contents of the unconscious are concerned, it can be argued that, in the novel we can find the search for the anima as well as the confrontation with the dark side of the personality. The road to individuation is partially accomplished by the integration of these unconscious elements into the consciousness of the main character. Charging Elk manages to adapt to the new country by means of assimilating into his ego consciousness, the demands of the new socio-cultural environment.

By making the decision to focus upon the positive aspects of existence, he manages to transcend the pain and hurt caused by external events: his dislocation from home and his abandonment by the Wild West Show community.

I have argued that, the alternation between freedom and imprisonment functions in a similar way. This is why it can be said that, the two concepts can be interpreted as two sides of the same coin: desire. The desire for freedom can also be interpreted as a desire for power. This power to transcend suffering comes from the accomplishment of the inner work. This can have as a result the liberation from both inner and outer coercive forces.

As far as the critical interpretation of the author Gilbert Durand is concerned, it is worth arguing that, he talks about different ways of achieving knowledge: the indirect knowledge which is represented by the sign, allegory, and symbol and the direct one which is focused on the decorative function of the object. The symbol is representative of a sacred story, while the sign represents an ornament and plays an exclusively decorative function. This decorative function has no intrinsic value. The allegory is a way of representing an abstract idea 
which cannot be grasped directly. The feminine in the novel appears as the symbol of individuation and, thus, triggers a balancing response in the main character's personality. On the other hand, the sign can be associated to what Foucault call the object. The object is influenced by power relations and represents a mechanical piece in the fabric of society. This is why it has no symbolic meaning and causes suffering.

In the novel analyzed the indirect thinking can be associated to the concept of imagination, while the direct one, to the objective perception of reality. However, I argue that, reality shapes itself in the form of the imagination because the main character is using his mind in order to recreate his world. The novel can represent a form of reconstruction of reality after the experience of traumatic events. In this case, the reconstruction is successful and the end of the novel finds the character at peace with his life situation. It can also be argued that, Charging Elk is using indirect thinking in order to transcend the objective world where he experiences suffering.

As far as the adaptation to the new country is concerned, the novel can be interpreted as a story of assimilation in a new cultural environment. On the other hand, it can also be interpreted as a story about power and the way in which power influences the dynamics of social relationships. If we are to consider the views of the critic Pierre Bourdieu about the way in which knowledge circulates in society, it can be argued that, the cultural and spiritual "capital" of the main character is determining his social and economic position in the new country. The fact that he has no rights is reflective of the fact that he is seen as having no spiritual capital in the context of the new cultural setting. The critic Pierre Bourdieu talks about the concept of "religious capital", which is represented by the organizations which distribute sacred knowledge. Religious needs are compared to any other needs that must be met in society. The way in which these needs are met is through the distribution of the religious capital. This religious capital is not evenly distributed because of the hierarchical social system in which society functions. It is important to remark that, this distribution is dependent upon social and economic conditions.

In the novel, the main character is dispossessed of his native religious and cultural capital by the American mainstream authorities. In spite of this fact, he manages to obtain compensation by means of his imagining skills. It is due to his internal resistance of spiritual colonization that he manages to survive the suffering caused by the events in which he is involved in. The sociologist Pierre Bourdieu talks about the fact that language can also be considered a means of communication but, at the same time, a means of distributing knowledge and power. In this respect, knowledge can be associated to value. This is why the distribution of value is achieved by means of distributing knowledge. The fact that Charging Elk has no knowledge of French is also contributing to his immersion into suffering. Value and the possession of such cultural and religious capital can be a symbol of power and freedom.

It is interesting to remark that, such power and freedom, come by means of surviving the earlier difficult stages of dispossession, illness, and imprisonment. Charging Elk is left alone in a foreign land where he possesses no social, cultural, or religious capital. However, the fact that he survives is a proof that there is a common universal "capital" that can be used in any circumstance. This universal capital represents the same spiritual values and does not change according to the socio-cultural space in which it is present. This capital is represented in the novel by Charging Elk's focus on the authentic spiritual values of his own culture. It seems paradoxical that he survives by means of staying true to his own spiritual tradition and not by trying to copy or chase a different form of religious capital. 


\section{Conclusion}

In conclusion, it can be argued that, imagination plays a central role in the development of the story. The alternation between freedom and imprisonment can only be explained by the concept of imagination. It is problematic to rationalize this alternation because the feelings of imprisonment and freedom are experienced in the same environment. This journey of the main character is based upon the paradoxical nature of reality. Reality can be reconstructed according to the perspective of the mind. The power dynamic is unstable when imagination is taken into account. This is because the time-space reality is transcended when the mind evokes images such as memories from a different time and space or archetypes of the collective unconscious. These images combined with the emotions which they produce, are literally restructuring reality. It is also interesting to notice how the previous time and space perspective where Charging Elk has experienced happiness, becomes also a place of suffering after it has been colonized by the US authorities. I would suggest that, in order to recreate the feeling of this earlier happy time space reality, imagination plays a central role. This is why I also argued that, what the mind remembers is the only account for ever having existed freedom in the time space reality. Due to these facts, it becomes clear that any environment becomes hostile after some time and that the alternation between freedom and imprisonment is an ongoing natural process.

This process resembles the cyclic rhythms of nature. All environments are doomed for change because sooner or later freedom becomes enslavement if the time-space perspective, it is not reinterpreted and reevaluated. This why I conclude that, like the novel Charging Elk, all works of art are incomplete, which is why they can be interpreted and invested with aesthetic value. This aesthetic value can only be perceived from the perspective of an observer who is willing to use his/her imaginative abilities.

\section{References}

Durand, G. (1999). Aventurile imaginii Imaginaţia simbolica (The adventures of the imaginary. The symbolic imagination). Bucureşti: Ed. Nemira.

Foucault, M. (1983). The subject and power. In H. Dreyfus and P. Rabinow (Eds.), Michel Foucault: Beyond structuralism and Hermeneutics (2nd ed., pp. 208-226). Chicago: The University of Chicago Press.

Halbwachs, M. (1992). On collective memory. London: The University of Chicago Press, Ltd..

Jung, C. G. (1981). The archetypes and the collective unconscious. Princeton: Princeton University Press.

Rey, T. (2007). Bourdieu in religion imposing faith and religion on the genesis of religion. London and New York, Routledge. Welch, J. (2000). The heart song of Charging Elk. Osoyoos, Canada: Doubleday. 